Internat. J. Math. \& Math. Sci.

Vol. 23, No. 3 (2000) 175-180

S0161171200001964

(C) Hindawi Publishing Corp.

\title{
LACUNARY STATISTICAL CONVERGENCE AND INCLUSION PROPERTIES BETWEEN LACUNARY METHODS
}

\author{
JINLU LI
}

(Received 6 August 1998)

\begin{abstract}
A lacunary sequence is an increasing integer sequence $\theta=\left\{k_{r}\right\}$ such that $k_{r}-$ $k_{r-1} \rightarrow \infty$ as $r \rightarrow \infty$. A sequence $x$ is called $s_{\theta}$-convergent to $L$ provided that for each $\varepsilon>0, \lim _{r}\left(1 /\left(k_{r}-k_{r-1}\right)\right)\left\{\right.$ the number of $\left.k_{r-1}<k \leq k_{r}:\left|x_{k}-L\right| \geq \varepsilon\right\}=0$. In this paper, we study the general description of inclusion between two arbitrary lacunary sequences convergent.
\end{abstract}

Keywords and phrases. Lacunary sequence, statistical convergence.

2000 Mathematics Subject Classification. Primary 40A05, 40C05, 40D05; Secondary 11B05.

1. Introduction. An increasing integer sequence $\theta=\left\{k_{r}\right\}$ is called a lacunary sequence if it satisfies that $k_{0}=0$ and $h_{r}:=k_{r}-k_{r-1} \rightarrow \infty$ as $r \rightarrow \infty$. Throughout this paper, we follow the notation used in [7]. A sequence $x$ is called $S_{\theta}$-convergent to $L$ provided that for each $\varepsilon>0$. The intervals determined by $\theta$ is denoted by $I_{r}:=\left(k_{r-1}, k_{r}\right]$ and the ratio $k_{r} / k_{r-1}$ is abbreviated by $q_{r}$. For a finite set $E,|E|$ indicate the number of elements in $E$.

Let $\theta$ be a lacunary sequence, a complex number sequence $x$ is said to be $S_{\theta^{-}}$ convergent to $L$ provided that for each $\varepsilon>0$.

$$
\lim _{r}\left(\frac{1}{h_{r}}\right)\left\{\text { the number of } k_{r-1}<k \leq k_{r}:\left|x_{k}-L\right| \geq \varepsilon\right\}=0 .
$$

In this case we write $S_{\theta}-\lim x=L$ or $x_{k} \rightarrow L\left(S_{\theta}\right)$, and we define

$$
S_{\theta}=\left\{x: S_{\theta}-\lim x=L, \text { for some } L\right\} .
$$

In [4] it is defined that the lacunary sequence $\beta=\left\{l_{r}\right\}$ is called a lacunary refinement of the lacunary sequence $\theta=\left\{k_{r}\right\}$ if $\left\{k_{r}\right\} \subseteq\left\{l_{r}\right\}$. In [7], after the inclusion relationship between $S_{\theta}$ and $S_{\beta}$ is studied for a special case if $\beta=\left\{l_{r}\right\}$ is a lacunary refinement of the lacunary sequence $\theta=\left\{k_{r}\right\}$, an open problem is raised: what is the general description of the inclusion between two arbitrary lacunary methods. In this paper, we study the inclusion properties of different lacunary methods and solve this open problem.

2. Inclusion properties. If $\beta=\left\{l_{r}\right\}$ is a lacunary refinement of the lacunary sequence $\theta=\left\{k_{r}\right\}$, it is shown by [7, Thm. 7] that $x_{k} \rightarrow L\left(S_{\beta}\right)$ implies $x_{k} \rightarrow L\left(S_{\theta}\right)$, i.e., $S_{\beta} \subseteq S_{\theta}$. We begin this section by giving the converse of [7, Thm. 7]. 
THEOREM 1. Suppose $\beta=\left\{l_{r}\right\}$ is a lacunary refinement of the lacunary sequence $\theta=\left\{k_{r}\right\}$. Let $I_{r}:=\left(k_{r-1}, k_{r}\right]$ and $J_{r}:=\left(l_{r-1}, l_{r}\right], r=1,2,3, \ldots$ If there exists $\delta>0$ such that

$$
\frac{\left|J_{j}\right|}{\left|I_{i}\right|} \geq \delta \quad \text { for every } J_{j} \subseteq I_{i} .
$$

Then $x_{k} \rightarrow L\left(S_{\theta}\right)$ implies $x_{k} \rightarrow L\left(S_{\beta}\right)$, i.e., $S_{\theta} \subseteq S_{\beta}$.

Proof. For any $\varepsilon>0$, and every $J_{j}$, we can find $I_{i}$ such that $J_{j} \subseteq I_{i}$; then we have

$$
\begin{aligned}
\left(\frac{1}{\left|J_{j}\right|}\right)\left|\left\{k \in J_{j}:\left|x_{k}-L\right| \geq \varepsilon\right\}\right| & =\left(\frac{\left|I_{i}\right|}{\left|J_{j}\right|}\right)\left(\frac{1}{\left|I_{i}\right|}\right)\left|\left\{k \in J_{j}:\left|x_{k}-L\right| \geq \varepsilon\right\}\right| \\
& \leq\left(\frac{\left|I_{i}\right|}{\left|J_{j}\right|}\right)\left(\frac{1}{\left|I_{i}\right|}\right)\left|\left\{k \in I_{i}:\left|x_{k}-L\right| \geq \varepsilon\right\}\right| \\
& \leq\left(\frac{1}{\delta}\right)\left(\frac{1}{\left|I_{i}\right|}\right)\left|\left\{k \in I_{i}:\left|x_{k}-L\right| \geq \varepsilon\right\}\right|,
\end{aligned}
$$

and the proof completes immediately.

THEOREM 2. Suppose $\beta=\left\{l_{r}\right\}, \theta=\left\{k_{r}\right\}$ are two lacunary sequences. Let $I_{r}:=\left(k_{r-1}\right.$, $\left.k_{r}\right], J_{r}:=\left(l_{r-1}, l_{r}\right], r=1,2,3, \ldots$, and $I_{i j}=I_{i} \cap J_{j}, i, j=1,2,3, \ldots$ If there exists $\delta>0$, such that

$$
\frac{\left|I_{i j}\right|}{\left|I_{i}\right|} \geq \delta \quad \text { for every } i, j=1,2,3, \ldots, \text { provided } I_{i j} \neq \varnothing .
$$

Then $x_{k} \rightarrow L\left(S_{\theta}\right)$ implies $x_{k} \rightarrow L\left(S_{\beta}\right)$, i.e., $S_{\theta} \subseteq S_{\beta}$.

Proof. Let $\alpha=\beta \cup \theta$. Then $\alpha$ is a lacunary refinement of the lacunary sequence $\beta$, also $\theta$. The interval sequence of $\alpha$ is $\left\{I_{i j}=I_{i} \cap J_{j}: I_{i j} \neq \varnothing\right\}$. From Theorem 1, the condition in Theorem 2: $\left|I_{i j}\right| /\left|I_{i}\right| \geq \delta$, for every $i, j=1,2,3, \ldots$, provided $I_{i j} \neq \varnothing$ yields that $x_{k} \rightarrow L\left(S_{\theta}\right)$ implies $x_{k} \rightarrow L\left(S_{\alpha}\right)$. Since $\alpha$ is also a lacunary refinement of the lacunary sequence $\beta$, from [4, Thm. 7] we have that $x_{k} \rightarrow L\left(S_{\alpha}\right)$ implies $x_{k} \rightarrow L\left(S_{\beta}\right)$. The proof follows immediately.

In Theorem 2, if the condition is replaced by $\left|I_{i j}\right| /\left|J_{j}\right| \geq \delta$, for every $i, j=1,2,3, \ldots$, provided $I_{i j} \neq \varnothing$, it can be seen that $x_{k} \rightarrow L\left(S_{\beta}\right)$ implies $x_{k} \rightarrow L\left(S_{\theta}\right)$. Combining this remark and Theorem 2 we get the following theorem.

THEOREM 3. Suppose $\beta=\left\{l_{r}\right\}, \theta=\left\{k_{r}\right\}$ are two lacunary sequences. Let $I_{r}:=\left(k_{r-1}\right.$, $\left.k_{r}\right], J_{r}:=\left(l_{r-1}, l_{r}\right], r=1,2,3, \ldots$, and $I_{i j}=I_{i} \cap J_{j}, i, j=1,2,3, \ldots$ If there exists $\delta>0$, such that

$$
\frac{\left|I_{i j}\right|}{\left(\left|I_{i}\right|+\left|J_{j}\right|\right)} \geq \delta, \quad \text { for every } i, j=1,2,3, \ldots, \text { provided } I_{i j} \neq \varnothing .
$$

Then $x_{k} \rightarrow L\left(S_{\theta}\right)$ if and only if $x_{k} \rightarrow L\left(S_{\beta}\right)$, i.e., $S_{\theta}=S_{\beta}$.

Theorem 2 provides a sufficient condition for lacunary sequence $\beta=\left\{l_{r}\right\}, \theta=\left\{k_{r}\right\}$ to yield the inclusion relation $S_{\theta} \subseteq S_{\beta}$. In Theorem 4 we give some necessary and sufficient conditions for two lacunary sequences to have the relationship. 
TheOREM 4. Suppose $\beta=\left\{l_{r}\right\}, \theta=\left\{k_{r}\right\}$ are two lacunary sequences. Let $J_{r}:=$ $\left(l_{r-1}, l_{r}\right], I_{r}:=\left(k_{r-1}, k_{r}\right], r=1,2,3, \ldots$ There exists a sequence $x$ and a number $L$ such that $S_{\beta}-\lim x=L$ and $S_{\theta}-\lim x \neq L$, if and only if there exist $\left\{S_{i}\right\},\left\{t_{i}\right\} \subseteq N$ and $\delta>0$ which satisfies the following conditions:

(i) $J_{s_{i}} \cap I_{t_{i}} \neq \varnothing$;

(ii) $\lim _{i}\left|J_{s_{i}}\right| /\left|I_{t_{i}}\right|=\infty$;

(iii) $\left|J_{s_{i}} \cap I_{t_{i}}\right| /\left|I_{t_{i}}\right| \geq \delta, i=1,2,3, \ldots$.

\section{ProOF}

(I) NECESSITY. If there exists a sequence $x=\left\{x_{k}\right\}$ and a number $L$ such that $S_{\beta}-$ $\lim x=L$ and $S_{\theta}-\lim x \neq L$, then there exist a subsequence $\left\{t_{i}\right\} \subseteq N, \varepsilon>0$, and $\delta>0$, such that

$$
\left(\frac{1}{\left|I_{t_{i}}\right|}\right)\left|\left\{k \in I_{t_{i}}:\left|x_{k}-L\right| \geq \varepsilon\right\}\right| \geq \delta, \quad i=1,2,3, \ldots .
$$

For each $t_{i}$, there exist a positive integer $s_{i}$ and a whole number $r_{i}$ such that

$$
J_{s_{i}+j} \cap I_{t_{i}} \neq \phi \quad \text { for every } j=0,1,2, \ldots, i=1,2,3, \ldots
$$

Then, we can write

$$
\begin{aligned}
\delta \leq & \left(\frac{1}{\left|I_{t_{i}}\right|}\right)\left|\left\{k \in I_{t_{i}}:\left|x_{k}-L\right| \geq \varepsilon\right\}\right| \\
= & \left(\frac{1}{\left|I_{t_{i}}\right|}\right)\left|\left\{k \in\left(\bigcup_{j=0}^{n} J_{s_{i}+j}\right) \cap I_{t_{i}}:\left|x_{k}-L\right| \geq \varepsilon\right\}\right| \\
= & \left(\frac{1}{\left|I_{t_{i}}\right|}\right) \sum_{j=0}^{r_{i}}\left|\left\{k \in J_{s_{i}+j} \cap I_{t_{i}}:\left|x_{k}-L\right| \geq \varepsilon\right\}\right| \\
= & \left(\frac{1}{\left|I_{t_{i}}\right|}\right) \sum_{j=0, r_{i}}\left|\left\{k \in J_{s_{i}+j} \cap I_{t_{i}}:\left|x_{k}-L\right| \geq \varepsilon\right\}\right| \\
& +\left(\frac{1}{\left|I_{t_{i}}\right|}\right) \sum_{0<j<r_{i}}\left|\left\{k \in J_{s_{i}+j} \cap I_{t_{i}}:\left|x_{k}-L\right| \geq \varepsilon\right\}\right| \\
= & \left(\frac{1}{\left|I_{t_{i}}\right|}\right) \sum_{j=0, r_{i}}\left|\left\{k \in J_{s_{i}+j} \cap I_{t_{i}}:\left|x_{k}-L\right| \geq \varepsilon\right\}\right| \\
& +\left(\frac{1}{\left|I_{t_{i}}\right|}\right) \sum_{0<j<r_{i}}\left|\left\{k \in J_{s_{i}+j}:\left|x_{k}-L\right| \geq \varepsilon\right\}\right| \\
= & \left(\frac{1}{\left|I_{t_{i}}\right|}\right) \sum_{j=0, r_{i}}\left|\left\{k \in J_{s_{i}+j} \cap I_{t_{i}}:\left|x_{k}-L\right| \geq \varepsilon\right\}\right| \\
& +\sum_{0<j<r_{i}}\left(\frac{\left|J_{s_{i}+j}\right|}{\left|I_{t_{i}}\right|}\right)\left(\frac{1}{\left|J_{s_{i}+j}\right|}\right)\left|\left\{k \in J_{s_{i}+j}:\left|x_{k}-L\right| \geq \varepsilon\right\}\right| .
\end{aligned}
$$

Since $S_{\beta}-\lim x=L$, if $s_{i}+j$ is sufficiently large, we have

$$
\left(\frac{1}{\left|J_{s_{i}+j}\right|}\right) \sum_{0<j<r_{i}}\left|\left\{k \in J_{s_{i}+j}:\left|x_{k}-L\right| \geq \varepsilon\right\}\right|<\frac{\delta}{2} .
$$


It can be seen that $\sum_{o<j<r_{i}}\left(\left|J_{s_{i}+j}\right| /\left|I_{t_{i}}\right|\right) \leq 1$. Hence, we get

$$
\begin{aligned}
\delta & \leq\left(\frac{1}{\left|I_{t_{i}}\right|}\right)\left|\left\{k \in I_{t_{i}}:\left|x_{k}-L\right| \geq \varepsilon\right\}\right| \\
& \leq\left(\frac{1}{\left|I_{t_{i}}\right|}\right) \sum_{j=o, r_{i}}\left|\left\{k \in J_{s_{i}+j} \cap I_{t_{i}}:\left|x_{k}-L\right| \geq \varepsilon\right\}\right|+\frac{\delta}{2} .
\end{aligned}
$$

This implies that $\left(1 /\left|I_{t_{i}}\right|\right) \sum_{j=o, r_{i}}\left|\left\{k \in J_{s_{i}+j} \cap I_{t_{i}}:\left|x_{k}-L\right| \geq \varepsilon\right\}\right| \geq \delta / 2$, which ensures that at least one of the following inequalities hold:

$$
\left(\frac{1}{\left|I_{t_{i}}\right|}\right)\left|\left\{k \in J_{s_{i}} \cap I_{t_{i}}:\left|x_{k}-L\right| \geq \varepsilon\right\}\right| \geq \frac{\delta}{4},
$$

or

$$
\left(\frac{1}{\left|I_{t_{i}}\right|}\right)\left|\left\{k \in J_{s_{i}+r_{i}} \cap I_{t_{i}}:\left|x_{k}-L\right| \geq \varepsilon\right\}\right| \geq \frac{\delta}{4} .
$$

Suppose the first one holds, i.e., $\left(1 /\left|I_{t_{i}}\right|\right)\left|\left\{k \in J_{s_{i}} \cap I_{t_{i}}:\left|x_{k}-L\right| \geq \varepsilon\right\}\right| \geq \delta / 4$. From this inequality and since $\left|\left\{k \in J_{s_{i}} \cap I_{t_{i}}:\left|x_{k}-L\right| \geq \varepsilon\right\}\right| \leq\left|J_{s_{i}} \cap I_{t_{i}}\right|$, we conclude that $\delta / 4 \leq\left|J_{s_{i}} \cap I_{t_{i}}\right| /\left|I_{t_{i}}\right|$ which proves (iii).

For such $s_{i}, t_{i}$ chosen in the proof of (iii), from (2.10), we have

$$
\begin{aligned}
\frac{\delta}{4} & \leq\left(\frac{1}{\left|I_{t_{i}}\right|}\right)\left|\left\{k \in J_{s_{i}} \cap I_{t_{i}}:\left|x_{k}-L\right| \geq \varepsilon\right\}\right| \\
& \leq\left(\frac{\left|J_{s_{i}}\right|}{\left|I_{t_{i}}\right|}\right)\left(\frac{1}{\left|J_{s_{i}}\right|}\right)\left|\left\{k \in J_{s_{i}} \cap I_{t_{i}}:\left|x_{k}-L\right| \geq \varepsilon\right\}\right| .
\end{aligned}
$$

Since $\left(1 /\left|J_{s_{i}}\right|\right)\left|\left\{k \in J_{s_{i}} \cap I_{t_{i}}:\left|x_{k}-L\right| \geq \varepsilon\right\}\right| \rightarrow 0$, as $i \rightarrow \infty$, (2.12) implies $\left|J_{s_{i}}\right| /\left|I_{t_{i}}\right| \rightarrow \infty$, as $i \rightarrow \infty$, which proves (ii). It is clear that the intervals $J_{s_{i}}, I_{t_{i}}$ chosen in the proof of (iii) satisfy (i).

(II) SUFFICIENCY. Suppose that for the two lacunary sequences $\beta=\left\{l_{r}\right\}, \theta=\left\{k_{r}\right\}$ there exist sequences $\left\{s_{i}\right\},\left\{t_{i}\right\} \subseteq N$ and $\delta>0$ which satisfy the conditions (i), (ii), and (iii) in the theorem. Define

$$
x_{k}= \begin{cases}1, & \text { if } k \in J_{s_{i}} \cap I_{t_{i}} \\ 0, & \text { otherwise }\end{cases}
$$

For any $1<\varepsilon<0$, if $j \neq s_{i}$ for any $i=1,2,3, \ldots,\left(1 /\left|J_{j}\right|\right)\left|\left\{k \in J_{j}:\left|x_{k}-0\right| \geq \varepsilon\right\}\right|=$ $|\varnothing| /\left|J_{j}\right|=0$; if $j=s_{i}$, for some $i,\left(1 /\left|J_{s_{i}}\right|\right)\left|\left\{k \in J_{s_{i}} \cap:\left|x_{k}-0\right| \geq \varepsilon\right\}\right|=\left|J_{s_{i}} \cap I_{t_{i}}\right| /\left|J_{s_{i}}\right| \leq$ $\left|I_{t_{i}}\right| /\left|J_{s_{i}}\right| \rightarrow 0$. Hence $S_{\beta}-\lim x=0$. But $\left(1 /\left|I_{t_{i}}\right|\right)\left|\left\{k \in I_{t_{i}}:\left|x_{k}-0\right| \geq \varepsilon\right\}\right|=\mid J_{s_{i}} \cap$ $I_{t_{i}}|/| I_{t_{i}} \mid \geq \delta$, for $i=1,2,3, \ldots$. This implies that $S_{\theta}-\lim x \neq 0$.

COROLlaRY 1. Suppose $\beta=\left\{l_{r}\right\}, \theta=\left\{k_{r}\right\}$ are two lacunary sequences. Let $J_{r}:=$ $\left(l_{r-1}, l_{r}\right], I_{r}:=\left(k_{r-1}, k_{r}\right], r=1,2,3, \ldots$ If there exist $\left\{s_{i}\right\},\left\{t_{i}\right\} \subseteq N$ such that $J_{s_{i}} \supseteq I_{t_{i}}, i=$ $1,2,3, \ldots$, and $\lim _{i}\left|J_{s_{i}}\right| /\left|I_{t_{i}}\right|=\infty$, then there exists a sequence $x$ and a number $L$ such that $S_{\beta}-\lim x=L$ and $S_{\theta}-\lim x \neq L$.

Proof. The conditions of the Corollary 1 imply all the conditions of the Theorem 4 . So the corollary follow Theorem 4 immediately. 
3. The Space $X_{\theta}$. Let $\theta=\left\{k_{r}\right\}$ be a lacunary sequence. A $S_{\theta}$-convergent sequence $x$ is not necessary to be bounded. The superior norm in $l^{\infty}$ does not apply to the set $S_{\theta}$, where $l^{\infty}$ is the set of bounded complex numbers. Hence we need to define a new norm on a suitable space. If we apply the superior norm in the subset of $l^{\infty}, S_{\theta} \cap l^{\infty}$, we get a closed subset of $l^{\infty}$.

THEOREM 5. $S_{\theta} \cap l^{\infty}$ is a closed subset of $l^{\infty}$ with the superior norm.

Proof. Suppose $\left\{x^{n}\right\} \subseteq S_{\theta} \cap l^{\infty}$ is a convergent sequence and it converges to $x \in$ $l^{\infty}$. We need to prove that $x \in S_{\theta} \cap l$. Assume $x^{n} \rightarrow L_{n}\left(S_{\theta}\right), n=1,2,3, \ldots$. Take a positive decreasing convergent sequence $\left\{\varepsilon_{n}\right\}$, then for every $n=1,2,3, \ldots$, there is a positive integer $m_{n}$, such that if $n \geq m_{n}$, then $\left\|x-x^{n}\right\|_{\infty} \leq \varepsilon_{n} / 4$. Without loss of generality, we just assume $m_{n}=n$. For the fixed $n$, there is $k_{r_{n}}$ such that

$$
\begin{gathered}
\left(\frac{1}{h_{r_{n}}}\right)\left|\left\{k \in I_{r_{n}}:\left|x_{k}^{n}-L_{n}\right| \geq \frac{\varepsilon_{n}}{4}\right\}\right|<\frac{1}{4}, \\
\left(\frac{1}{h_{r_{n}}}\right)\left|\left\{k \in I_{r_{n}}:\left|x_{k}^{n+1}-L_{n+1}\right| \geq \frac{\varepsilon_{n+1}}{4}\right\}\right|<\frac{1}{4} .
\end{gathered}
$$

Then

$$
\left\{k \in I_{r_{n}}:\left|x_{k}^{n}-L_{n}\right|<\frac{\varepsilon_{n}}{4}\right\} \cap\left\{k \in I_{r_{n}}:\left|x_{k}^{n+1}-L_{n+1}\right|<\frac{\varepsilon_{n+1}}{4}\right\} \neq \varnothing .
$$

Pick a member $k$ in this intersection, we can write

$$
\begin{aligned}
\left|L_{n}-L_{n+1}\right| & \leq\left|x_{k}^{n}-L_{n}\right|+\left|x_{k}^{n+1}-L_{n+1}\right|+\left|x_{k}^{n}-x_{k}^{n+1}\right| \\
& \leq\left|x_{k}^{n}-L_{n}\right|+\left|x_{k}^{n+1}-L_{n+1}\right|+|| x-x^{n}\left\|_{\infty}+\right\| x-x^{n+1} \|_{\infty} \\
& \leq \frac{\varepsilon_{n}}{4}+\frac{\varepsilon_{n+1}}{4}+\frac{\varepsilon_{n}}{4}+\frac{\varepsilon_{n+1}}{4} \leq \varepsilon_{n} .
\end{aligned}
$$

This implies that $\left\{L_{n}\right\}$ is a Cauchy sequence in $C$, and there is a complex number $L$ such that $L_{n} \rightarrow L$, as $n \rightarrow \infty$. We need to prove that $x \rightarrow L\left(S_{\theta}\right)$. For any $\varepsilon>0$, there is $n$, such that $\varepsilon_{n}<\varepsilon / 4,\left|x-x^{n} \|_{\infty}<\varepsilon / 4,\right| L_{n}-L \mid<\varepsilon / 4$, then

$$
\begin{aligned}
\left(\frac{1}{h_{r}}\right) \mid\{k & \left.\in I_{r}:|x-L| \geq \varepsilon\right\} \mid \\
& \leq\left(\frac{1}{h_{r}}\right)\left|\left\{k \in I_{r}:\left|x^{n}-L_{n}\right|+\left\|x-x^{n}\right\|_{\infty}+\left|L_{n}-L\right| \geq \varepsilon\right\}\right| \\
& \leq\left(\frac{1}{h_{r}}\right)\left|\left\{k \in I_{r}:\left|x^{n}-L_{n}\right|+\frac{\varepsilon}{4}+\frac{\varepsilon}{4} \geq \varepsilon\right\}\right| \\
& =\left(\frac{1}{h_{r}}\right)\left|\left\{k \in I_{r}:\left|x^{n}-L_{n}\right| \geq \frac{\varepsilon}{2}\right\}\right| \rightarrow 0, \quad \text { as } r \rightarrow \infty .
\end{aligned}
$$

This gives that $x \rightarrow L\left(S_{\theta}\right)$, which completes the proof.

Let $\theta=\left\{k_{r}\right\}$ be a lacunary sequence. for every $L \in C$, define

$$
X_{L}:=\left\{x \in S_{\theta}: x \rightarrow L\left(S_{\theta}\right)\right\} \quad \text { and } \quad X_{\theta}:=\left\{X_{L}: L \in C\right\} .
$$

If $x \rightarrow L\left(S_{\theta}\right), y \rightarrow K\left(S_{\theta}\right)$, and $a \in C$, it can be seen that

$$
x+y \rightarrow(L+K)\left(S_{\theta}\right) \quad \text { and } \quad a x \longrightarrow a L\left(S_{\theta}\right),
$$


where $x+y=\left\{x_{n}+y_{n}\right\}$ and $a x=\left\{a x_{n}\right\}$. Then the following definitions on $X_{\theta}$ well defined

$$
X_{L}+X_{K}:=X_{L+K} \quad \text { and } \quad a X_{L}=X_{a L}
$$

For every $X_{L} \in X_{\theta}$, we define a norm of it by $\left\|X_{L}\right\|:=|L|$.

THEOREM 6. With the addition, scalar multiplication and norm defined on $X_{\theta}$ as above, $X_{\theta}$ is a Banach space.

Proof. To prove that $X_{\theta}$ is complete norm space, we just notice that $\left\{X_{L_{n}}\right\}$ is a Cauchy sequence of $X_{\theta}$, if and only if $\left\{L_{n}\right\}$ is a Cauchy sequence of $C$, and for any complex number $L$, the sequence with constant terms $L$ should converge to $L\left(S_{\theta}\right)$. Rest of the proof is clear.

ACKNOwLEDgement. The author wish to thank Prof. J. A. Fridy for his communication and useful suggestions.

\section{REFERENCES}

[1] R. C. Buck, Generalized asymptotic density, Amer. J. Math. 75 (1953), 335-346. MR 14,854f. Zbl 050.05901.

[2] J. S. Connor, The statistical and strong p-Cesaro convergence of sequences, Analysis 8 (1988), no. 1-2, 47-63. MR 89k:40013. Zbl 653.40001.

[3] H. Fast, Sur la convergence statistique, Colloq. Math. 2 (1951), 241-244. MR 14,29c. Zbl 044.33605.

[4] A. R. Freedman, J. J. Sember, and M. Raphael, Some Cesaro-type summability spaces, Proc. London Math. Soc. 37 (1978), no. 3, 508-520. MR 80c:40007. Zbl 424.40008.

[5] J. A. Fridy, On statistical convergence, Analysis 5 (1985), no. 4, 301-313. MR 87b:40001. Zbl 588.40001.

[6] J. A. Fridy and H. I. Miller, A matrix characterization of statistical convergence, Analysis 11 (1991), no. 1, 59-66. MR 92e:40001. Zbl 727.40001.

[7] J. A. Fridy and C. Orhan, Lacunary statistical convergence, Pacific J. Math. 160 (1993), no. 1, 43-51. MR 94j:40014. Zbl 794.60012.

Li: Department of Mathematics, Shawnee State University, Portsmouth, OH 45662, USA

E-mail address: $\mathrm{j} 1 \mathrm{i} @$ shawnee.edu 


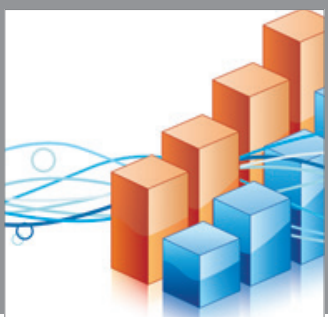

Advances in

Operations Research

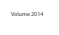

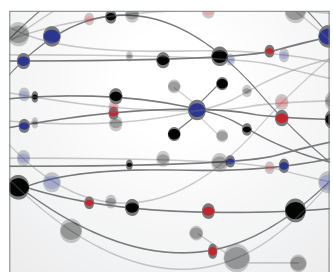

\section{The Scientific} World Journal
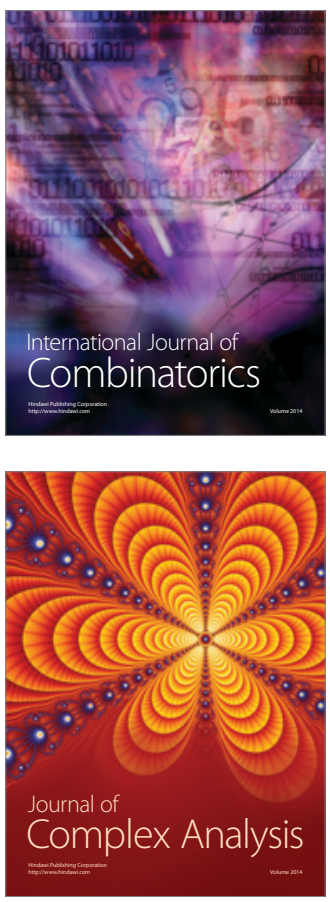

International Journal of

Mathematics and

Mathematical

Sciences
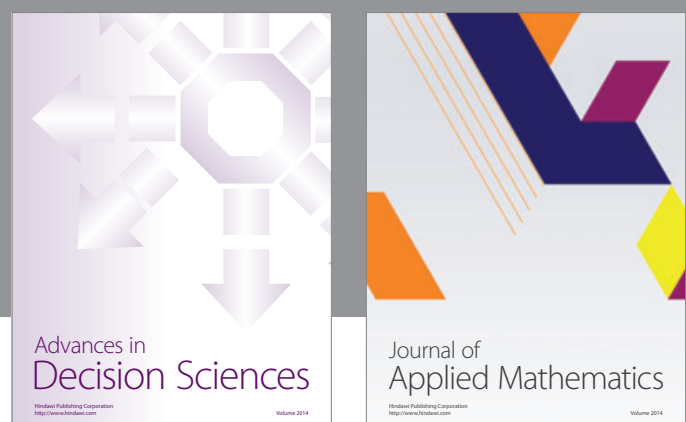

Journal of

Applied Mathematics
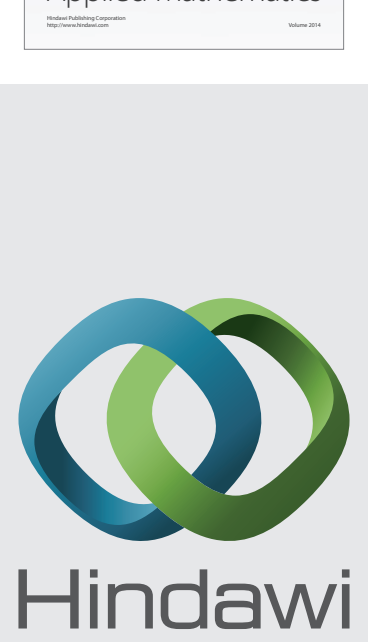

Submit your manuscripts at http://www.hindawi.com
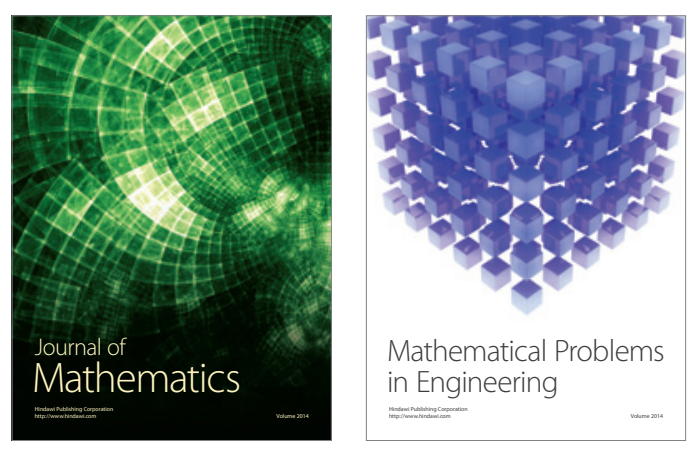

Mathematical Problems in Engineering
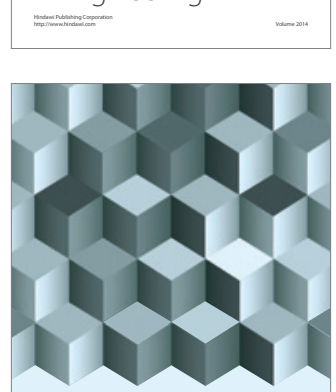

Journal of

Function Spaces
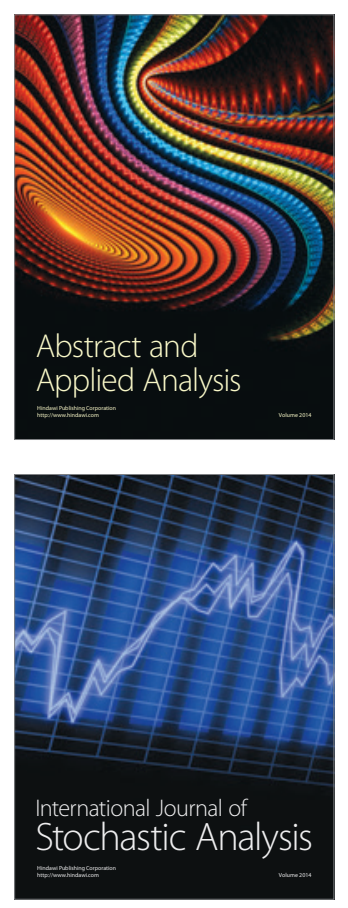

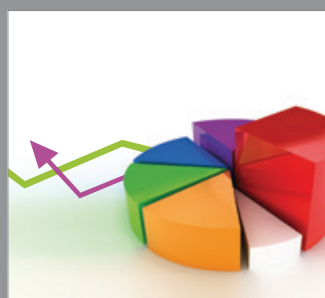

ournal of

Probability and Statistics

Promensencen
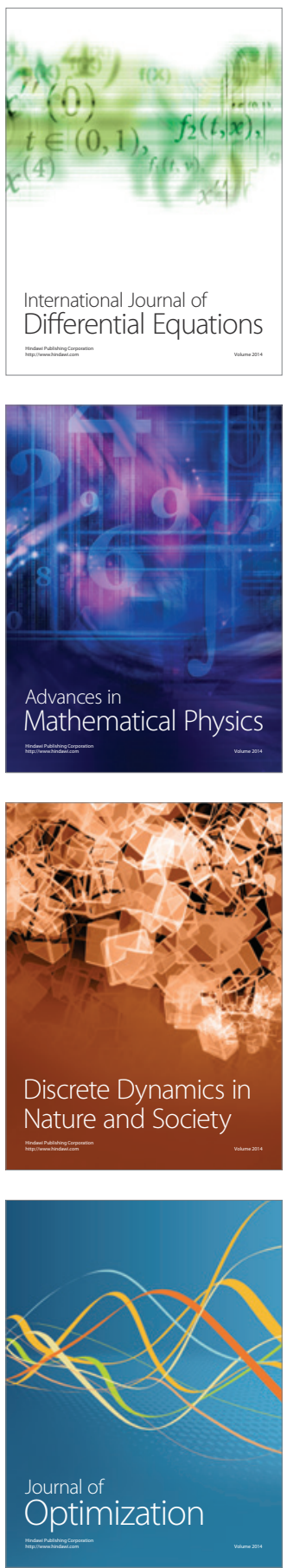